\title{
Compliance with the New 2017 Child and Adult Care Food Program Standards for Infants and Children before Implementation
}

\author{
Danielle L. Lee, MPH, RD,' Klara Gurzo, MS,' Sallie Yoshida, DrPH, RD, \\ Elyse Homel Vitale, MPH, Ken Hecht, JD, and Lorrene D. Ritchie, PhD, RD'
}

\section{Abstract}

Background: Nationally, child care providers serve nutritious food to over 4.5 million children each day as part of the federal Child and Adult Care Food Program (CACFP). As implementation of the first major revisions to the CACFP standards occurs in 2017, understanding how to support compliance is critical.

Methods: In 2016, surveys were sent to a randomly selected sample of 2400 licensed California child care centers and homes. Compliance with the new CACFP standards and best practices for infants under 1 year and children 1-5 years of age was assessed. Also, compliance was compared by CACFP participation, and between centers and homes. Interviews were conducted with 16 CACFP stakeholders to further understand barriers to and facilitators of compliance.

Results: Analysis of 680 survey responses revealed that compliance with most individual CACFP standards and best practices examined was high ( $>60 \%$ of sites). However, compliance with all new standards was low ( $<23 \%$ of sites). Compliance was lowest for timing of introduction of solids to infants, not serving sweet grains, serving yogurt low in sugar, and serving appropriate milk types to children. When different, compliance was higher for sites participating in CACFP versus nonparticipants, and for centers versus homes. Although providers indicated few barriers, stakeholders identified the need for incremental and easily accessible trainings that provide practical tips on implementation.

Conclusion: Training on a number of topics is needed to achieve full implementation of the new CACFP standards to ensure that young children in child care have access to healthier meals and snacks.

Keywords: Child and Adult Care Food Program; child care; nutrition; policies; practices

\section{Introduction}

H ealthy eating in early childhood is essential for optimal growth and to establish lifelong habits. The high prevalence of overweight among children ${ }^{1-3}$ has led policymakers to target nutrition in child care settings. ${ }^{4-6}$ In the United States $\sim 175,000$ licensed child care sites participate in the federal Child and Adult Care Food Program (CACFP), receiving reimbursement for feeding 4.5 million children daily in 2017.7 In California about half of family child care homes (hereafter referred to as homes) and one-third of child care centers (hereafter referred to as centers) participate in CACFP. ${ }^{8}$ In addition, in many states, including California, all licensed child care centers not participating in CACFP are required to follow the CACFP standards. ${ }^{9}$

Mandated by the 2010 Healthy, Hunger-Free Kids Act, the first major revisions to the CACFP standards went into effect in October 2017. ${ }^{10}$ These changes aligned CACFP standards with the Dietary Guidelines for Americans as recommended by the Institute of Medicine (IOM). ${ }^{11}$ The new required standards and optional best practices focus on increasing fruit, vegetables, and whole grains, and decreasing added sugar in snacks and meals served to children.

Understanding how to support compliance is critical. Only one study to date has assessed providers' compliance

\footnotetext{
'Nutrition Policy Institute, University of California Division of Agriculture and Natural Resources, Berkeley, CA.

${ }^{2}$ The Sarah Samuels Center for Public Health Research and Evaluation, Oakland, CA.

${ }^{3}$ California Food Policy Advocates, Oakland, CA.
} 
with new CACFP standards. In 2015, Schwartz et al. found that nutrition practices in 38 Connecticut centers participating in CACFP were not in alignment with the IOM recommendations. ${ }^{12}$ This study involved a relatively small sample of centers and did not include child care homes and infant standards. All child care centers in Connecticutregardless of whether participating in CACFP or not-are required to meet CACFP standards ${ }^{13}$; therefore another limitation of this study is that non-CACFP participating sites were not assessed.

To inform successful implementation of the new CACFP standards and best practices for infants and children, the present study assessed child care providers' compliance before implementation, perceived barriers, and desired resources. Included were centers and homes participatingand not participating - in CACFP and child care stakeholders in California. Compliance was compared between sites participating in CACFP and not, and between centers and homes. California was ideal for the study as the state with the most child care sites in the nation. ${ }^{7}$

\section{Methods}

\section{Overview}

A survey was administered to a sample of licensed child care providers. Child care experts with knowledge about CACFP were interviewed to further understand challenges and resources needed to implement the CACFP changes. The study was approved by the University of California, Davis Institutional Review Board.

\section{Survey Sample Selection}

A California Department of Social Services database was used to identify all licensed child care centers and homes in the state. A California Department of Education database was used to identify all licensed centers and homes participating in CACFP. Sites were placed in one of the following six categories before random selection: Head Start Centers (in CACFP), state preschools (that can participate in CACFP or follow the federal school meal program guidelines which generally meet or exceed those of CACFP), other centers in and not in CACFP, and homes in and not in CACFP. Using a random number generator, a sample of 2400 providers (for approximately equal representation from each category) was selected from over 50,000 statewide. The randomly selected sample included 1800 centers (including Head Start and state preschools) and 600 homes.

\section{Survey Content}

Questions were adapted from previous pilot-tested surveys ${ }^{14,15}$ based on a validated instrument. ${ }^{16}$ Providers reported all foods and beverages served by the child care site or brought from home by parents to infants (under 1 year) and, separately, to children (1-5 years), at breakfast, lunch, supper, and snacks on the day before completing the survey. Providers were asked what has or will help support implementation of select CACFP standards and best practices and what makes implementation difficult.

\section{Survey Data Collection}

In fall 2016, all sites were mailed a postcard in Spanish and English with a link to an online survey (Qualtrics, Version 08-2016, 2016). A follow-up e-mail was also sent to sites with e-mail addresses $(n=1248)$. Two months later, paper surveys (in English for centers; in English and Spanish for homes) were mailed to providers who had not completed the survey online $(n=2245)$. Providers were contacted by phone when the response rate by child care category was below $10 \%$. Providers were compensated with a $\$ 5$ gift card.

\section{Survey Data Analysis}

Data from online surveys ( $n=155,6.5 \%$ response rate) were merged with paper surveys ( $n=581,25.9 \%$ response rate). Surveys were excluded from analysis due to duplication $(n=20)$. Overall survey response rate was $29.8 \%$, and includes subjects that responded to the survey at least once in any form. Surveys were also excluded if $>60 \%$ of the first section of the survey asking about characteristics of the child care site was incomplete $(n=36)$ for a total of 680 . Of the 680 surveys included in the analysis, 564 $(31.3 \%)$ were from centers (33.1\% response rate), 116 $(19.3 \%)$ were from homes (20.0\% response rate). Thirteen family child care home providers $(11.2 \%)$ completed the survey in Spanish. Paper surveys were double entered to ensure data quality. To analyze compliance with infant standards and best practices, the sample was restricted to the subset of 680 caring for infants $(n=297)$.

Questions were recoded as binary variables to indicate compliance or noncompliance with each CACFP standard or best practice and nonresponses were not included in the denominator. Compliance was also computed across all standards and further for at least four of five infant standards, and at least five and six of seven child standards to evaluate how far the providers were from full compliance. Compliance was not computed across all best practices since these are not required, but encouraged. Differences in compliance between sites participating in CACFP and not and between centers and homes were assessed using logistic regression adjusted for site being a center or home (for the CACFP vs. non-CACFP comparison), CACFP versus non-CACFP participant (for the center vs. home comparison), total number of infants and children per site, and years of operation. Standard errors were clustered on the ZIP-code level to take into consideration similarities in food environments within ZIP codes. This results in a conservative estimation. $p$-Values $<0.05$ were considered significant. Survey responses marked "other (write-in)" were recoded to either one of the appropriate answer responses or a new variable identified by themes of writein responses. For those that did not include a write-in response, their response remained coded as "other". Data were analyzed using SAS version 9.4 (SAS Institute, Inc., Cary, NC, 2013). 


\section{Stakeholder Interviews}

Interviews were conducted in spring 2017 with 16 child care experts knowledgeable about CACFP, including federal and state-level CACFP administrators, child care providers, unions organizing child care workers, resource and referral organizations, and others. Interview questions were developed by the research team with input from CACFP experts to illuminate anticipated challenges and resources needed to implement the CACFP changes and factors likely to influence compliance. Questions were modified for clarity from several initial interviews. All interviews were conducted by telephone by two researchers; one leading the interview and the other taking notes. Interviews lasted 30 minutes on average, were audiorecorded and transcribed verbatim. Conceptual analysis ${ }^{17}$ a process used to determine the presence of certain concepts within sets of tests known as codes or themes, was applied to examine responses for each open-ended question. Data were analyzed using Nvivo version 10.0 (QSR International Pty Ltd., 1999-2014). Interviewees were not compensated for their participation.

\section{Results}

\section{Characteristics of Child Care Sites}

Descriptive characteristics of the subset of sites caring for infants under 1 year of age $(n=297)$ and the full sample ( $n=680$ caring for children 1-5 years of age) are shown in Table 1. Most ( $\sim 90 \%$ ) surveys were completed by the site director or owner. A majority of all sites $(82.9 \%)$ were centers and nearly three-quarters participated in CACFP. Sites cared for an average of 7 infants and 78 children 1-5 years of age. Over half of sites provided both full-day and half-day care. Most $(>85 \%)$ had been in operation for over 5 years. Of sites not participating in CACFP, 57\% had not heard about the new standards, whereas over half of CACFP-participating sites reported knowing somewhat $(26 \%)$ or a lot $(30 \%)$ about them.

\section{Compliance with Infant Standards and Best Practices}

Five standards and one best practice were assessed at sites caring for infants (Table 2 ). Nearly $6 \%$ were compliant with all infant standards, whereas $41.8 \%$ were compliant with at least four standards. Compliance was high ( $\sim 70 \%$ or more sites) for each individual standard with the exception of serving solid foods at around 6 months of age, with which one-quarter of sites were compliant. Serving yogurt low in sugar (determined by asking about plain yogurt without fruit flavoring or added sugar to approximate the USDA definition of $<23 \mathrm{~g}$ of total sugar per $6 \mathrm{oz}$ ) was the only infant standard for which compliance was significantly higher for CACFP compared with non-CACFP sites (85.2\% vs. 63.3\%). Serving fruit and/or vegetables as snacks was the only infant standard for which compliance was significantly higher for centers than homes $(72.0 \%$ vs. $52.8 \%)$. Nearly all sites implemented the best practice to not serve sugarsweetened beverages to infants $(98.6 \%)$.

\section{Compliance with Child Standards and Best Practices}

Sites caring for children 1-5 years of age were assessed for compliance with eight standards and five best practices (Table 3). Overall compliance with seven standards was calculated instead of all eight standards because one standard was restricted to only providers serving children 1 - to 2-years of age. Compliance with seven standards was $22.2 \%$, whereas $77.0 \%$ of sites were compliant with at least five and $52.9 \%$ were compliant with at least six standards. Significantly more CACFP than non-CACFP sites were compliant with at least five, six or all seven standards, and centers were significantly more compliant than homes for at least five or six of the seven standards. Serving only unflavored whole milk to children 1-2 years of age was the standard with the lowest compliance $(54.5 \%)$; instead, sites reported usually serving lower fat milks.

CACFP sites had higher compliance than non-CACFP sites for providing at least one serving of whole grains each day (90.0\% vs. $80.4 \%)$ and serving only unflavored low-fat or fat-free milk to children $2-5$ years of age $(73.5 \%$ vs. $43.0 \%)$. Centers, compared with homes, had higher compliance with serving breakfast cereals low in sugar $(\leq 6 \mathrm{~g}$ sugar per dry ounce) $(87.4 \%$ vs. $75.7 \%)$, making drinking water available and offered throughout the day $(81.9 \%$ vs. $55.1 \%)$, and not providing grainbased desserts $(68.2 \%$ vs. $53.6 \%)$.

Implementation of best practices ranged from $46.0 \%$ providing at least two servings of whole grain-rich foods per day as snacks to $75.0 \%$ for offering whole fruits more often than juice. CACFP sites reported higher implementation than non-CACFP sites for providing whole fruit more often than juice $(78.7 \%$ vs. $66.3 \%)$, and for serving at least two whole grains each day (51.8\% vs. $31.8 \%)$. Non-CACFP sites compared with CACFP sites reported higher implementation for having a fruit or vegetable (not including canned fruits in syrup, sweetened applesauce, or fried potatoes) as snacks ( $73.3 \%$ vs. $55.4 \%)$.

\section{Barriers to Compliance}

Response options to questions about difficulties implementing standards included not hard, parent preference, infant/child preference, not a provider priority, or other (write in). For all standards, the most common response was that implementation was not hard (Table 4). Parent preference was reported by $44.4 \%$ of sites as a barrier to serving solid foods to infants when 6 months old; however, CACFP allows solids before 6 months if parents deem their infant developmentally ready. ${ }^{18}$ The child standards identified as most difficult were serving low-sugar yogurt and serving whole grains. Child preference $(19.3 \%)$ and parent preference $(12.9 \%)$ were the most commonly reported 


\section{Table I. Characteristics of Child Care Sites}

\section{Characteristic}

Site director/owner responded to survey $(n, \%)$

Type of child care $(n, \%)$

\begin{tabular}{|c|c|c|c|c|c|c|}
\hline Head start ${ }^{d}$ & \multicolumn{3}{|c|}{$27(9.1 \%)$} & \multicolumn{3}{|c|}{$96(14.1 \%)$} \\
\hline State preschoole & \multicolumn{3}{|c|}{$32(10.8 \%)$} & \multicolumn{3}{|c|}{$132(19.4 \%)$} \\
\hline Center in CACFP & \multicolumn{3}{|c|}{$88(29.6 \%)$} & \multicolumn{3}{|c|}{$183(26.9 \%)$} \\
\hline Center not in CACFP & \multicolumn{3}{|c|}{$76(25.6 \%)$} & \multicolumn{3}{|c|}{$153(22.5 \%)$} \\
\hline Home in CACFP & \multicolumn{3}{|c|}{$45(15.2 \%)$} & \multicolumn{3}{|c|}{$68(10.0 \%)$} \\
\hline Home not in CACFP & \multicolumn{3}{|c|}{$29(9.8 \%)$} & \multicolumn{3}{|c|}{$48(7.1 \%)$} \\
\hline Participate in CACFP $(n, \%)$ & \multicolumn{3}{|c|}{$192(64.7 \%)$} & \multicolumn{3}{|c|}{$479(70.4 \%)$} \\
\hline Number of infants (mean, SD) & \multicolumn{3}{|c|}{$n=273$} & \multicolumn{3}{|c|}{$n=619$} \\
\hline $0-5$ months & \multicolumn{3}{|c|}{$2.9(14.7)$} & \multicolumn{3}{|c|}{$2.9(14.7)$} \\
\hline 6-1I months & \multicolumn{3}{|c|}{$4.4(5.9)$} & \multicolumn{3}{|c|}{$4.4(5.9)$} \\
\hline Total & \multicolumn{3}{|c|}{$7.3(15.8)$} & \multicolumn{3}{|c|}{$7.3(15.8)$} \\
\hline Number of children (mean, SD) & \multicolumn{3}{|c|}{$n=273$} & \multicolumn{3}{|c|}{$n=619$} \\
\hline I2-23 months & \multicolumn{3}{|c|}{$9.4(9.3)$} & \multicolumn{3}{|c|}{$5.2(8.7)$} \\
\hline 24-35 months & \multicolumn{3}{|c|}{$14.5(15.4)$} & \multicolumn{3}{|c|}{$10.6(18.4)$} \\
\hline $3-5$ years & \multicolumn{3}{|c|}{$47.8(137.9)$} & \multicolumn{3}{|c|}{$62.1(162.6)$} \\
\hline Total & & $71.7(147.1)$ & & & $77.9(172.7)$ & \\
\hline Number of staff (mean, SD) & & $\begin{array}{c}17.4(22.5) \\
n=293\end{array}$ & & & $\begin{array}{c}14.8(23.0) \\
n=673\end{array}$ & \\
\hline Type of care provided ( $n, \%)$ & & $n=293$ & & & $n=665$ & \\
\hline Full-day care only & & $92(31.4 \%)$ & & & $190(28.6 \%)$ & \\
\hline Half-day care only & & $3(1.0 \%)$ & & & $122(18.4 \%)$ & \\
\hline Full-day and half-day & & $198(67.6 \%)$ & & & $353(53.1 \%)$ & \\
\hline Years in operation $(n, \%)$ & & $n=296$ & & & $n=672$ & \\
\hline$<$ l year & & $5(1.7 \%)$ & & & $7(1.0 \%)$ & \\
\hline I up to 3 years & & $22(7.4 \%)$ & & & $36(5.4 \%)$ & \\
\hline 3 up to 5 years & & 17 (5.7\%) & & & $32(4.8 \%)$ & \\
\hline$\geq 5$ years & & $252(85.1 \%)$ & & & $597(88.8 \%)$ & \\
\hline $\begin{array}{l}\text { Knowledge of new CACFP } \\
\text { standards }(n, \%)\end{array}$ & $\begin{array}{c}\text { All } \\
(n=290)\end{array}$ & $\begin{array}{l}\text { CACFP } \\
(n=188)\end{array}$ & $\begin{array}{c}\text { Non-CACFP } \\
(n=102)\end{array}$ & $\begin{array}{c}\text { All } \\
(n=657)\end{array}$ & $\begin{array}{l}\text { CACFP } \\
(n=462)\end{array}$ & $\begin{array}{l}\text { Non-CACFP } \\
(n=195)\end{array}$ \\
\hline None & $80(27.6 \%)$ & $27(14.4 \%)$ & $53(52.0 \%)$ & $192(29.2 \%)$ & $81(17.5 \%)$ & III (56.9\%) \\
\hline Very little or a little & $80(27.6 \%)$ & $47(25.0 \%)$ & $33(32.4 \%)$ & $180(27.4 \%)$ & $125(27.1 \%)$ & $55(28.2 \%)$ \\
\hline Somewhat & 59 (20.3\%) & $47(25.0 \%)$ & $12(11.8 \%)$ & $135(20.6 \%)$ & II 8 (25.5\%) & $17(8.7 \%)$ \\
\hline A lot & 7I (24.5\%) & 67 (35.6\%) & $4(3.9 \%)$ & $150(22.8 \%)$ & 138 (29.9\%) & $12(6.2 \%)$ \\
\hline
\end{tabular}

aSample size is indicated when less than the full sample due to missing survey responses; percentages may not sum to $100 \%$ due to rounding; infant sites are a subset of the total sites which cared for children $0-1 \mathrm{I}$ months of age; all sites cared for infants (0-I I months) and children (I-5 years). bOther responses included: cook, food program coordinator/manager, kitchen operations lead, nutrition manager.

'Other responses included: administrative assistant/aide, assistant director/principal, business manager, CACFP assistant, children services manager, cook, dietitian, food services manager.

${ }^{\mathrm{d}} \mathrm{Head}$ Start programs participate in CACFP and were categorized as a center participating in CACFP.

eState preschools participate in CACFP or the federal school meal programs and were categorized as a center participating in CACFP.

CACFP, Child and Adult Care Food Program.
Sites with infants $\left(n=297\right.$ sites $\left.^{a}\right)$

$277(94.5 \%)^{b}$

$n=293$

$597(89.2 \%)^{c}$

$n=669$ 


\begin{tabular}{|c|c|c|c|c|c|c|c|}
\hline & \multirow[b]{2}{*}{$\begin{array}{c}\text { All } \\
(n=297)\end{array}$} & \multicolumn{3}{|c|}{ Comparison by CACFP status } & \multicolumn{3}{|c|}{ Comparison of center vs. home } \\
\hline & & $\begin{array}{c}\text { CACFP } \\
(n=192)\end{array}$ & $\begin{array}{c}\text { Non-CACFP } \\
(n=105)\end{array}$ & $p$-Value & $\begin{array}{c}\text { Center } \\
(n=223)\end{array}$ & $\begin{array}{l}\text { Home } \\
(n=74)\end{array}$ & $p$-Value \\
\hline \multicolumn{8}{|l|}{ Standards ( $n, \%$ of sites) } \\
\hline Solids introduced at around 6 months of age $\mathrm{e}^{\mathrm{a}}$ & $70(25.4)$ & $42(23.7)$ & $28(28.3)$ & 0.41 & $49(24.0)$ & $21(29.2)$ & 0.23 \\
\hline Fruit, vegetable, or both as snack ${ }^{\mathrm{b}}$ & $195(67.2)$ & $128(67.4)$ & $67(67.0)$ & 0.65 & $157(72.0)$ & $38(52.8)$ & 0.008 \\
\hline No $100 \%$ juice & $219(77.7)$ & $137(74.9)$ & $82(82.8)$ & 0.12 & $170(80.2)$ & $49(70.0)$ & 0.24 \\
\hline Yogurt low in added sugarc & $217(77.5)$ & $155(85.2)$ & $62(63.3)$ & $<0.001$ & $167(78.0)$ & $50(75.8)$ & 0.99 \\
\hline No processed cheese & $209(74.6)$ & $|4|(77.5)$ & $68(69.4)$ & 0.07 & $155(72.4)$ & $54(81.8)$ & 0.10 \\
\hline Compliant with all five standards & $17(5.8)$ & $12(6.3)$ & $5(4.9)$ & 0.71 & $13(5.9)$ & $4(5.4)$ & 0.63 \\
\hline Compliant with at least four of five standards & $123(4 \mid .8)$ & $84(44.0)$ & 39 (37.9) & 0.41 & $96(43.6)$ & $27(36.5)$ & 0.81 \\
\hline \multicolumn{8}{|l|}{ Best practices ( $n, \%$ of sites) } \\
\hline No sugar-sweetened drinks ${ }^{d}$ & $279(98.6)$ & $183(98.9)$ & $96(98.0)$ & - e $^{-1}$ & $213(100.0)$ & $66(94.3)$ & - $^{\mathrm{e}}$ \\
\hline
\end{tabular}

Around $2 \%-5 \%$ of data were missing depending on standard/best practice. Significance assessed by logistic regressions adjusted for site being center or home (in case of CACFP vs. non-CACFP comparison), CACFP versus non-CACFP participant (in case of center vs. home comparison), total number of infants and children at site, years of operation, and cluster design on ZIP-code level.

Boldface type indicates a significant $p$-Value.

aSurvey question asked about usual practice with the following answer options: under 3 months, 4-6 months, 7-9 months, 10-12 months. Option of 4-6 month counted as being compliant.

${ }^{\mathrm{b}}$ This is a combination of survey responses that include serving baby food fruits/vegetables in a jar or pouch, fresh/canned in water or own juice/ frozen fruit, and/or fresh/frozen/canned/cooked/pureed vegetables.

'Survey question asked about yogurt flavored with fruit flavoring or added sugars followed by some examples. The USDA specifications for low-sugar yogurt: no more than $23 \mathrm{~g}$ total sugar per $6 \mathrm{oz}$.

${ }^{d}$ A California State Law (AB2084) has mandated the standard since $2012 .{ }^{19}$

e $p$-Values from adjusted analysis are not presented because there were no observations in one of the groups.

barriers to implementing the yogurt standard. Other common responses to the question on what makes it hard to serve yogurt low in sugar included difficulty in knowing what to buy (3.9\%), not available where shop (3.1\%) and higher cost (2.5\%) (included in the "other" column in Table 4). The most commonly reported barrier to serving whole grains was child preference $(18.2 \%)$. Other barriers to serving whole grains included higher cost $(6.0 \%)$ and not knowing what to buy (4.9\%) (included in the "other" column in Table 4).

The CACFP stakeholders who were interviewed reported inadequate time, difficulty training all sites, and additional paperwork to document compliance as the most likely barriers. Several said that the standards would be more difficult to implement in homes than centers due to more limited staffing and financial resources. Training concerns included lack of materials in different languages, lack of provider computer skills, and training not being accessible online for providers unable to attend in-person or webinar trainings.

\section{Resources Needed}

Table 5 lists resources that sites indicated would help them implement the standards. Of sites caring for infants
$44.3 \%$ said that no additional assistance was needed. Information for families was the most common resource requested by $28.0 \%$ of sites, followed by policy and written guidelines $(26.8 \%)$, and parent or family support $(25.1 \%)$. Of sites caring for children, $45.1 \%$ reported that no additional resources were needed. Policies/written guidelines $(22.7 \%)$ was the most common resource requested, followed by information for families $(20.5 \%)$, and parent or family support (18.9\%). For the standard on timing of introduction of solids to infants, information for families was the most common resource endorsed (by $44.9 \%$ of sites), followed by parent/family support $(41.0 \%)$. Information for families (22.7\%) and policies/written guidelines (21.9\%) were the most commonly requested resources to support the standard on limiting yogurt with added sugar. For the child standard to serve whole grains, the most common "other" need identified was recipes or tips for preparing whole grains that children like (28.1\%).

Stakeholders reported training and technical assistance as the most critical for successful implementation, citing the need to train providers on not only what the standards are, but how to implement them. Training topics identified as highest need were infant standards, what constitutes a 


\section{Table 3. Compliance with New Child and Adult Care Food Program Meal Pattern Standards and Best Practices for Sites with Children (I-5 Years of Age)}

\begin{tabular}{|c|c|c|c|c|c|c|c|}
\hline & \multirow[b]{2}{*}{$\begin{array}{c}\text { All } \\
(n=680)\end{array}$} & \multicolumn{3}{|c|}{ Comparison by CACFP status } & \multicolumn{3}{|c|}{ Comparison of center vs home } \\
\hline & & $\begin{array}{l}\text { CACFP } \\
(n=479)\end{array}$ & $\begin{array}{c}\text { Non-CACFP } \\
(n=20 I)\end{array}$ & p-Value & $\begin{array}{l}\text { Center } \\
(n=564)\end{array}$ & $\begin{array}{l}\text { Home } \\
(n=116)\end{array}$ & p-Value \\
\hline \multicolumn{8}{|l|}{ Standards ( $n, \%$ of sites) } \\
\hline Juice limited to once per day ${ }^{a}$ & $591(91.2)$ & $418(91.3)$ & $173(9 \mid .1)$ & 0.87 & $495(91.8)$ & $96(88.1)$ & 0.12 \\
\hline $\begin{array}{l}\text { At least one serving of grains per day } \\
\text { are whole grain rich }\end{array}$ & $567(87.2)$ & $415(90.0)$ & $152(80.4)$ & 0.003 & $468(86.7)$ & $99(90.0)$ & 0.20 \\
\hline Yogurt low in added sugarb & $424(65.5)$ & $306(67.0)$ & $118(62.1)$ & 0.53 & $363(67.7)$ & $61(55.0)$ & 0.16 \\
\hline Breakfast cereals low in added sugar ${ }^{c}$ & $557(85.4)$ & $402(87.0)$ & I55 (8I.6) & 0.28 & $473(87.4)$ & 84 (75.7) & 0.03 \\
\hline $\begin{array}{l}\text { Unflavored whole milk to children } \\
\text { I up to } 2 \text { years of age } \mathrm{e}^{\mathrm{d}}\end{array}$ & $225(54.5)$ & $165(56.9)$ & $60(48.8)$ & 0.21 & $176(56.4)$ & $49(48.5)$ & 0.96 \\
\hline $\begin{array}{l}\text { Unflavored low-fat or fat-free milk } \\
\text { to children } 2-5 \text { years of age }\end{array}$ & $402(65.1)$ & $328(73.5)$ & $74(43.0)$ & $<0.001$ & $335(65.4)$ & $67(63.2)$ & 0.36 \\
\hline $\begin{array}{l}\text { Drinking water offered and available } \\
\text { upon request throughout day }\end{array}$ & $502(77.4)$ & $367(80.1)$ & $135(70.7)$ & 0.08 & $442(81.9)$ & $60(55.1)$ & $<0.001$ \\
\hline No grain-based desserts & $427(65.7)$ & $303(65.7)$ & $124(65.6)$ & 0.39 & $368(68.2)$ & $59(53.6)$ & 0.04 \\
\hline $\begin{array}{l}\text { Compliant with all seven standards } \\
\text { (for seven standards, } n=586 \text { ) }\end{array}$ & $130(22.2)$ & $112(26.4)$ & $18(11.1)$ & 0.002 & $118(24.1)$ & $12(12.4)$ & 0.09 \\
\hline Compliant with at least six of seven standards & $310(52.9)$ & $240(56.6)$ & $70(43.2)$ & 0.04 & $279(57.1)$ & $31(32.0)$ & $<0.001$ \\
\hline Compliant with at least five of seven standards & $45 \mathrm{I}(77.0)$ & $344(81.1)$ & $107(66.1)$ & 0.01 & $392(80.2)$ & $59(60.8)$ & 0.02 \\
\hline \multicolumn{8}{|l|}{ Best practices ( $n, \%$ of sites) } \\
\hline Healthier fruit, vegetable, or both as snack ${ }^{f}$ & $370(60.7)$ & $238(55.4)$ & I32 (73.3) & $<0.00$ I & $297(58.6)$ & 73 (70.9) & 0.10 \\
\hline Whole fruits more often than juice & $469(75.0)$ & 347 (78.7) & $122(66.3)$ & 0.001 & 391 (74.9) & $78(75.7)$ & 0.39 \\
\hline $\begin{array}{l}\text { At least two servings of whole } \\
\text { grain-rich foods per day }\end{array}$ & $299(46.0)$ & $239(51.8)$ & $60(31.8)$ & $<0.001$ & $250(46.3)$ & $49(44.6)$ & 0.99 \\
\hline Only lean meats, nuts, and legumes & $405(62.2)$ & $280(60.6)$ & $125(66.1)$ & 0.18 & $343(63.5)$ & $62(55.9)$ & 0.56 \\
\hline No processed cheese & $410(64.1)$ & $284(62.8)$ & $126(67.0)$ & 0.26 & $339(63.6)$ & $71(66.4)$ & 0.43 \\
\hline
\end{tabular}

Around $4 \%-16 \%$ of data were missing depending on standard/best practice. Significance assessed by logistic regressions adjusted for site being center or home (in case of CACFP vs. non-CACFP comparison), CACFP versus non-CACFP participant (in case of center vs. home comparison), total number of infants and children at site, years of operation, and cluster design on ZIP-code level.

Boldface type indicates a significant $p$-Value.

${ }^{a}$ A California State Law (AB 2084) has mandated the standard since 2012.19

bSurvey question asked about yogurt flavored with fruit flavoring or added sugars followed by some examples. The USDA specifications for low sugar yogurt: no more than $23 \mathrm{~g}$ total sugar per $6 \mathrm{oz}$.

'Survey question asked about sweet cereals with examples of common cereals listed. USDA specifications for breakfast cereal: no more than $6 \mathrm{~g}$ sugar per I dry oz.

dExcludes participants $(n=207)$ who reported they do not provide care for children I-2 years of age.

eThe seven standards include: juice limited to once per day, at least one serving of grains per day are whole grain rich, yogurt low in added sugar, breakfast cereals low in added sugar, unflavored low-fat or fat-free milk served to children $2-5$ years of age, drinking water offered and available throughout the day, and no grain-based desserts. The whole milk standard for children I-2 years of age was excluded because not all respondents provided care for children I-2 years of age.

${ }^{f}$ Canned fruit in syrup (heavy or light) or sweetened applesauce and fried potatoes were not counted; this is a combination of three best practices: make at least one of the two required components of a snack, a vegetable, or a fruit; serve a variety of fruits; and serve a variety of vegetables.

whole grain, ounce equivalents of grains, grain-based desserts, and healthy snacks. Respondents cited webinars, followed by online, as the best ways to provide information to providers. Stakeholders emphasized that training should be offered often and include follow-up technical assistance.

\section{Discussion}

In our survey of licensed child care centers and homes caring for infants and young children in California, a majority of providers reported following most of the individual 


\section{Table 4. Factors that Make the New Infant and Child Standards Hard for Providers to Implement

\begin{tabular}{|c|c|c|c|c|} 
Not hard & $\begin{array}{c}\text { Parent preference } \\
\text { or practice }\end{array}$ & $\begin{array}{l}\text { Infant/child } \\
\text { preference }\end{array}$ & $\begin{array}{c}\text { Not a priority } \\
\text { for provider }\end{array}$ & Other $^{\mathrm{a}}$ \\
\hline \multicolumn{5}{c}{$(n, \%)$} \\
$\quad$
\end{tabular}

Infant standards

\begin{tabular}{|c|c|c|c|c|c|}
\hline Solids introduced at appropriate age $(n=279)$ & $162(58.1)$ & $124(44.4)$ & $4(1.4)$ & $12(4.3)$ & $10(3.6)$ \\
\hline Fruit, vegetable, or both as snack $(n=287)$ & $258(89.9)$ & $16(5.6)$ & $10(3.5)$ & $2(0.1)$ & $25(8.7)^{b}$ \\
\hline No $100 \%$ juice $(n=285)$ & $246(86.3)$ & $20(7.0)$ & $6(2.1)$ & $4(1.4)$ & $16(5.6)$ \\
\hline No processed cheese $(n=285)$ & $253(88.8)$ & $16(5.6)$ & $12(4.2)$ & $6(2.1)$ & $6(2.1)^{c}$ \\
\hline Average for infant standards & $229.8(80.8)$ & $44.0(15.7)$ & $8.0(2.8)$ & $6.0(2.0)$ & $14.3(5.0)$ \\
\hline \multicolumn{6}{|l|}{ Child standards } \\
\hline Juice limited $(n=635)$ & $524(82.5)$ & $59(9.3)$ & $60(9.5)$ & $18(2.8)$ & $21(3.3)^{d}$ \\
\hline Serve whole grains $(n=636)$ & $485(76.3)$ & - $^{\mathrm{e}}$ & $116(18.2)$ & $10(1.6)$ & $82(12.9)^{f}$ \\
\hline Limit yogurt with added sugarg $(n=632)$ & $433(68.1)$ & $82(12.9)$ & $122(19.3)$ & $9(1.4)$ & $58(9.2)^{\mathrm{h}}$ \\
\hline Limit breakfast cereals with added sugar $(n=630)$ & $537(84.3)$ & $39(6.1)$ & $67(10.5)$ & $5(0.8)$ & $21(3.3)^{i}$ \\
\hline $\begin{array}{l}\text { Unflavored whole milk to children } \\
\text { I-2 years of age }(n=393)^{\mathrm{j}}\end{array}$ & $363(92.4)$ & $13(3.3)$ & $7(1.8)$ & $2(0.5)$ & $22(7.5)^{k}$ \\
\hline $\begin{array}{l}\text { Unflavored low-fat or fat-free milk to } \\
\text { children } 2-5 \text { years of age }(n=625)\end{array}$ & $562(88.4)$ & $24(3.8)$ & $31(4.9)$ & $4(0.6)$ & $16(2.6)^{1}$ \\
\hline Limit grain-based desserts $(n=636)$ & $520(81.8)$ & $98(15.4)$ & $46(7.2)$ & $7(1.1)$ & $15(2.4)$ \\
\hline Average for child standards & $489.1(76.9)$ & $52.5(8.25)$ & $64.1(10.1)$ & $7.9(1.2)$ & $65.5(10.5)$ \\
\hline
\end{tabular}

Respondents were allowed to select multiple answer options so percentages do not add up to $100 \%$ across a row.

ancludes "other" write-in responses.

bIncludes additional response options on the survey: "not sure what kind of fruits and vegetables to buy," "fruits and vegetables are too difficult to prepare as a snack," "fruits and vegetables are expensive," "fruits and vegetables are hard for me to find," "infants are not served snack".

"Includes additional response option on the survey: "other cheese products are more expensive in comparison."

Includes additional response option on the survey: "higher cost of whole fruit."

eParent preference or practice was not an answer option on the survey.

fIncludes additional response options on the survey: "higher cost of whole grains," "whole grains are not available where I shop," "hard to tell which grains are whole grains."

sStandard also applies to infants.

hIncludes additional response options on the survey: "high cost of lower-sugar yogurt," "yogurt with less sugar not available where I shop for food," "hard to know which yogurt has less sugar."

'Includes additional response options on the survey: "high cost of low-sugar cereal," "cereal with less sugar not available where I shop for food," "hard to know which cereal has less sugar."

iTwo hundred seven survey respondents did not provide care for children I-2 years of age.

kIncludes additional response options on the survey: "high cost of unflavored whole milk", "unflavored whole milk not available where I shop", "I don't provide care for I year olds".

'Includes additional response options on the survey: "high cost of unflavored low-fat or fat-free milk", "unflavored low-fat or fat-free milk not available where I shop for food".

CACFP standards in advance of October 2017 when the new standards became requirements. Few barriers to implementing the standards were reported, which suggests that transitioning to the new CACFP standards will not be unduly difficult.

A higher percentage of sites participating in CACFP than not participating in CACFP were compliant with the new standards. This was expected (even though in California centers not on CACFP are supposed to follow CACFP standards) because centers on CACFP receive more training and monitoring than those not on the program. Less expectedly, for several standards a higher percentage of centers than homes were compliant with the new standards. This may reflect California's state 
Table 5. Factors that Influence Change in Implementing New Infant and Child Standards

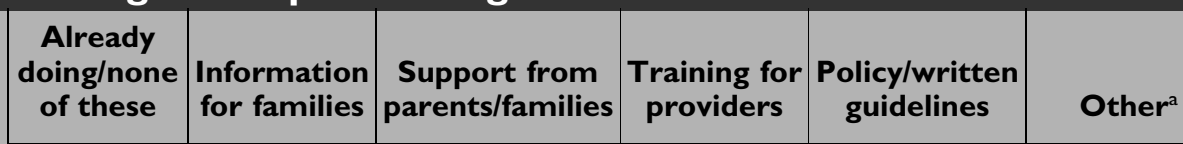

\begin{tabular}{|c|c|c|c|c|c|c|}
\hline & & & & & & \\
\hline & \multicolumn{6}{|c|}{$(n, \%)$} \\
\hline \multicolumn{7}{|l|}{ Infant standards } \\
\hline $\begin{array}{l}\text { Solids introduced at } \\
\text { appropriate age }(n=283)\end{array}$ & $67(23.7)$ & $127(44.9)$ & $116(41.0)$ & $53(18.7)$ & $108(38.2)$ & $10(3.5)$ \\
\hline Fruit, vegetable, or both as snack $(n=283)$ & $130(45.9)$ & $68(24.0)$ & $65(23.0)$ & $40(14.1)$ & $67(23.7)$ & $72(25.4)^{b}$ \\
\hline No $100 \%$ juice $(n=277)$ & $145(52.4)$ & $56(20.2)$ & $62(22.4)$ & $29(10.5)$ & $72(26.0)$ & $\mathrm{I}(0.4)$ \\
\hline No processed cheese $(n=280)$ & $154(55.0)$ & $64(22.9)$ & $39(13.9)$ & $33(11.8)$ & $54(19.3)$ & $48(17.1)^{b}$ \\
\hline Average for infant standards & $124.0(44.3)$ & $78.8(28.0)$ & $70.5(25.1)$ & $38.8(13.8)$ & $75.3(26.8)$ & $32.8(11.6)$ \\
\hline \multicolumn{7}{|l|}{ Child standards } \\
\hline Juice limited $(n=624)$ & $307(49.2)$ & $139(22.3)$ & $135(21.6)$ & $87(13.9)$ & $165(26.4)$ & $12(2.0)$ \\
\hline Serve whole grains $(n=630)$ & $233(37.0)$ & $138(21.9)$ & $98(15.5)$ & $107(17.0)$ & $130(20.6)$ & $225(35.7)^{b, c}$ \\
\hline $\begin{array}{l}\text { Limit yogurt that is not low in sugar } \\
(n=621)\end{array}$ & $286(46.1)$ & $|4|(22.7)$ & $|3|(2||)$. & $103(16.6)$ & $136(21.9)$ & $28(4.5)$ \\
\hline Limit sweet breakfast cereals $(n=610)$ & $310(50.8)$ & $126(20.7)$ & $117(19.2)$ & $93(15.3)$ & $139(22.8)$ & $9(1.5)$ \\
\hline $\begin{array}{l}\text { Unflavored whole milk to I up to } 2 \text { year } \\
\text { olds }(n=386)^{\text {d }}\end{array}$ & $208(53.9)$ & $72(18.7)$ & $59(15.3)$ & $64(16.6)$ & $101(26.2)$ & $14(3.6)$ \\
\hline $\begin{array}{l}\text { Unflavored low-fat or fat-free milk } \\
\text { to } 2-5 \text { year olds }(n=609)\end{array}$ & $299(49.1)$ & $118(19.4)$ & $119(19.5)$ & $93(15.3)$ & $168(27.6)$ & $16(2.6)$ \\
\hline Limit grain-based desserts $(n=63 \mathrm{I})$ & $313(49.6)$ & $156(24.7)$ & $162(25.7)$ & $88(14.0)$ & $145(23.0)$ & $9(1.4)$ \\
\hline Average for child standards & $279.4(45.1)$ & I27.| (20.5) & $117.3(18.9)$ & $90.7(14.7)$ & $140.6(22.7)$ & I54.I (24.9) \\
\hline
\end{tabular}

Respondents were allowed to select multiple answer options so percentages do not add up to $100 \%$ across a row.

ancludes write-in responses.

bIncludes additional response option on the survey: "recipes or preparing tips."

"Includes additional response option on the survey: "lessons for children."

'Two hundred seven survey respondents did not care for children I-2 years of age.

requirement that licensed centers not participating in CACFP must also follow CACFP standards; this is not true for licensed homes not participating in CACFP. Thus, with the broader reach of nutrition standards among centers than homes, there is broader awareness, too.

Relatively few sites, however, were compliant with all standards assessed $(<6 \%$ for all five infant standards and $<23 \%$ for all seven child standards examined). Furthermore, $<75 \%$ of sites were compliant for several standards: introducing solids at around 6 months of age; serving unflavored whole milk to children 1-2 years of age; serving unflavored low-fat or skim milk to children 2-5 years of age; serving yogurt with no more than $23 \mathrm{~g}$ of sugar per 6 $\mathrm{oz}$; and not serving grain-based desserts. The requirement to serve whole milk to $1-2$ year olds may be particularly confusing for providers in California. Since 2012, the California Healthy Beverages in Childcare Act (AB2084) ${ }^{19}$ requires that children 2 years and older are served unflavored $1 \%$ or skim milk. Stakeholder concerns mirrored reported rates of compliance, except for the requirement for whole grains. Because of confusion over what constitutes a grain that is whole grain rich, ${ }^{20,21}$ providers may have overreported compliance. Topics with relatively low compliance will likely require the most training and support.

Implementation was lower for optional best practices than for required standards. The notable exception was not serving sugar-sweetened beverages to infants. California's AB2084 disallows such beverages from being served in any licensed child care. ${ }^{19}$ The practice of serving sugarsweetened beverages may differ in states without such regulations. For example, a recent study in Pennsylvania found that more than half of child care centers surveyed offered sugar-sweetened beverages to children. ${ }^{22}$

Although sites did not report insufficient training as a barrier to implementing the new CACFP standards, stakeholders emphasized the need to help providers understand not only the content, but also how to operationalize the standards, expressing a concern that some providers might 
not realize what they did not know. Suggestions included providing cooking tips and recipes to prepare endorsed foods in ways that appeal to children. Although sites acknowledged few challenges in implementing the standards, child and parent preference were most frequently mentioned. Therefore, sites welcome information for families to increase support for the changes.

Few sites serving children (1.9\%) reported higher costs as a barrier to implementing the standards. However, we did not ask sites if serving food, in general, was cost prohibitive. Previous studies have shown providers have limited funding to support improving the nutritional quality of menus ${ }^{23}$ or experience increased food costs when menu quality increases. ${ }^{24,25}$

\section{Limitations}

Survey results may not fully capture practices at each site, as providers reported on a single day of foods and beverages served and may have biased reporting in favor of desirable rather than actual practice. Furthermore, providers were asked to report on all foods and beverages served, including those brought to child care by parents. While $<6 \%$ of sites reported usually serving foods from home, such foods are not subject to CACFP standards. Furthermore, while we attempted to gather information on foods and beverages that matched the standards, we were unable to achieve perfect alignment given the standards were finalized after the survey was conducted. For example, Graham crackers were included on the survey as a sweet grain; however subsequently the USDA decided to allow them. Conditional standards were not assessed (e.g., nondairy milk substitutes may be served to children with medical or special dietary needs). Finally, although sites were randomly selected to participate in the survey, it is unknown to what extent differences exist between respondents and nonrespondents.

\section{Conclusions}

While a majority of California's licensed child care centers and homes appear ready for the new CACFP standards, most frequent concerns exist relating to the appropriate milk for different ages and to the requirements for grains. Based upon information from stakeholders, we identified several resources to help achieve full implementation, including offer trainings on an ongoing basis, use a range of formats with a focus on how to implement the standards, and include information for families on the new standards.

\section{Acknowledgments}

This project was funded by the Robert Wood Johnson Foundation Healthy Eating Research Program Grant \#73245 with additional support from the National Institutes of Health: NIH R25 \#HL125451: Short Term Research Education Program to Increase Diversity in Health Related Research/Bay Area Summer Research Internship Program,
California Institute for Regenerative Medicine (CIRM): \#EDUC 3-08399, Leveraging Investment in High School Training Summer Program to Accelerate Regenerative Medicine Knowledge (Light-a-SPARK), and Doris Duke Charitable Foundation (DDCF) Clinical Research Continuum: High School to College Program, Grant \#2016-143, and The CHORI Summer Research Internship Program. The authors are grateful to the UC Berkeley School of Public Health Graduate Student, Gemma DiMatteo, who assisted with tool development and data collection, and undergraduate student fellows, Azar Dixit, Adrian Valderrama, Stella Van Den Eeden, and Tyler Takata for their work on the project.

\section{Author Disclosure Statement}

No competing financial interests exist.

\section{References}

1. Fryar CD, Carroll MD, Ogden CL. Prevalence of overweight and obesity among children and adolescents: United States, 1963-1965 through 2011-2012. Health E-Stats. 2014. Available at https:// cdc.gov/nchs/data/hestat/obesity_child_11_12/obesity_child_11_12 .htm Last accessed June 12, 2018.

2. Stettler N, Zemel BS, Kumanyika S, et al. Infant weight gain and childhood overweight status in a multicenter, cohort study. $\mathrm{Pe}$ diatrics 2002;109:194-199.

3. Pan L, Park S, Slayton R, et al. Trends in severe obesity among children aged 2 to 4 years enrolled in Special Supplemental Nutrition Program for Women, Infants, and Children from 200 to 2014. JAMA Pediatr 2018;172:232-238.

4. American Dietetic Association Position of the American Dietetic Association. Benchmarks for nutrition programs in child care settings. J Am Diet Assoc 2005;105:979-986.

5. Briley M, McAllaster M. Nutrition and the child care setting. J Am Diet Assoc 2011;111:1298-1300.

6. Story M, Kaphingst KM, French S. The role of child care settings in obesity prevention. Future Child 2006;16:143-168.

7. Rosso R, Henchy G. Child and adult care food program: Participation trends 2016. The Food Research and Action Center (FRAC). Available at http://frac.org/wp-content/uploads/cacfpparticipation-trends-2016.pdf Last accessed June 12, 2018.

8. Gutierrez H, Vitale EH, Shimada T. Early access to healthy foods: Trends in California's child and adult care food program 2010 to 2016. California Food Policy Advocates. 2017. Available at https://cfpa.net/ChildNutrition/ChildNutrition_CFPAPublications/ CFPA-CACFPTrends-2017.pdf Last accessed June 12, 2018.

9. Frost N, Cradock A, Neelon SB. Healthy eating, active play, screen time best practices. Public Health Law Center. Available at http:// publichealthlawcenter.org/heal/ChildCareMaps.html Last accessed June 12, 2018.

10. Child and Adult Care Food Program. Meal Pattern Revisions Related to the Healthy, Hunger-Free Kids Act of 2010. 81 Federal Register 79. (25 April 2016), pp. 24348-24383.

11. Institute of Medicine. Child and adult care food program: Aligning dietary guidance for all. The National Academies Press. 2011. Available at https://doi.org/10.17226/12959 Last accessed June 12, 2018. 
12. Schwartz MB, Henderson KE, Grode G, et al. Comparing current practice to recommendations for the child and adult care food program. Child Obes 2015;11:491-498.

13. State of Connecticut, Office of Early Childhood, Division of Licensing. Statutes and regulations. Child care centers and group child care homes. 2017. Available at http://ct.gov/oec/lib/oec/licensing/ childcare/centers_statsregs.pdf Last accessed June 12, 2018.

14. Ritchie LD, Boyle M, Chandran K, et al. Participation in the child and adult care food program is associated with more nutritious foods and beverages in child care. Child Obes 2012;8:224-229.

15. Ritchie LD, Yoshida S, Sharma S, et al. Drinking water in California child care sites before and after 2011-2012 beverage policy. Prev Chronic Dis 2015;12:140548.

16. Benjamin SE, Neelon B, Ball SC, et al. Reliability and validity of a nutrition and physical activity environmental self-assessment for child care. Int J Behav Nutr Phys Act 2007;4:29.

17. Krueger RA. Analyzing and Reporting Focus Group Results. Sage Publications, Thousand Oaks, CA, 1997.

18. United States Department of Agriculture. CACFP 02-2018. Feeding infants and meal pattern requirements in the child and adult care food program; questions and answers. October 19, 2017. Available at https://fns-prod.azureedge.net/sites/default/files/cacfp/ CACFP02-2018os.pdf Last accessed June 12, 2018.

19. State of California. AB2084 assembly bill. February 18, 2010. Available at http://leginfo.ca.gov/pub/09-10/bill/asm/ab_2051-2100/ab_ 2084_bill_20100930_chaptered.html Last accessed June 12, 2018.

20. Kantor LS, Variyam JN, Allshouse JE, et al. Choose a variety of grains daily, especially whole grains: A challenge for consumers. $J$ Nutr 2001;131(2S-1):473S-486S.
21. Korczak R, Marquart L, Slavin JL, et al. Thinking critically about whole-grain definitions: Summary report of an interdisciplinary roundtable discussion at the 2015 Whole Grains Summit. Am J Clin Nutr 2016;104:1508-1514.

22. Lutzkanin KM, Myers AK, Schaefer EW, et al. Report of sugarsweetened beverages offered in Pennsylvania childcare centers. Clin Pediatr (Phila) 2016;55:518-524.

23. Dev DA, Byrd-Williams C, Ramsay S, et al. Engaging parents to promote children's nutrition and health. Am J Health Promot 2017; 31:153-162.

24. Monsivais P, Johnson DB. Improving nutrition in home child care: Are food costs a barrier. Public Health Nutr 2012; 15:370-376.

25. Monsivais P, Kirkpatrick S, Johnson DB. More nutritious food is served in child-care homes receiving higher federal food subsidies. J Am Diet Assoc 2011;111:721-726.

Address correspondence to:

Lorrene D. Ritchie, PhD, RD

Nutrition Policy Institute

University of California Division of Agriculture and Natural Resources

2115 Milvia Street, Suite 301

Berkeley, CA 94704

E-mail:1ritchie@ucanr.edu 